\title{
LOCALIZAÇÃO DE ESCOLAS PÚBLICAS: SÍNTESE DE ALGUMAS LINHAS DE EXPERIÊNCIAS NO BRASIL
}

\author{
Nélio Domingues Pizzolato * \\ Departamento de Engenharia Industrial - PUC-RIO \\ Rio de Janeiro - RJ \\ Programa Pós-Graduação Engenharia Civil - UFF \\ Niterói - RJ \\ ndp@venus.rdc.puc-rio.br
}

\author{
Ana Gláucia Barros \\ Departamento de Educação - Univ. Estadual do Ceará \\ Fortaleza - CE \\ Fabrício Broseghini Barcelos \\ Departamento de Engenharia Industrial - PUC-RIO \\ Rio de Janeiro - RJ
}

\author{
Alberto Gabbay Canen \\ Programa de Engenharia de Produção - COPPE/UFRJ \\ Rio de Janeiro - RJ \\ * Corresponding author/autor para quem as correspondências devem ser encaminhadas \\ Recebido em 06/2003; aceito em 02/2004 após 1 revisão \\ Received June 2003; accepted February 2004 after one revision
}

\begin{abstract}
Resumo
Este artigo relata uma proposta metodológica para localização de escolas públicas em áreas urbanas. A metodologia é subdividida em duas partes que se complementam: a avaliação da atual localização e uma proposta de relocalização. Além da revisão metodológica, o artigo faz uma síntese de cinco estudos feitos em cidades ou regiões brasileiras, quais sejam: Nova Iguaçu, Nilópolis, Niterói, Ilha do Governador e Fortaleza. O estudo destaca a evolução metodológica, desde o uso dos mapas até o emprego de softwares da família SIG (Sistemas de Informação Geográficos), como o ArcView e o GeoRedes. O estudo destaca ainda a importância gerencial de cada um dos cinco estudos.
\end{abstract}

Palavras-chave: localização de escolas; modelo das p-medianas.

\begin{abstract}
This paper reports a methodology for locating public elementary schools in urban settings. The proposed methodology is divided in two complementary parts: the evaluation of the current location and a relocation proposal. In addition to the methodological review the paper outlines five studies made in Brazilian cities or large areas, which are: Nova Iguaçu, Nilópolis, Niterói, Ilha do Governador and Fortaleza. The study emphasizes the methodological evolution from paper maps up to geocoded maps using softwares of the GIS family (Geographic Information System) such as ArcView and GeoRedes. The study also evaluates the managerial importance of each one of the five studies.
\end{abstract}

Keywords: school location; p-median model. 


\section{Introdução}

A educação é amplamente reconhecida como a base para o desenvolvimento de uma nação e a prioridade que lhe deve ser atribuída constitui-se uma unanimidade política no Brasil. Existe, inclusive, o consenso de que a inserção do país no bloco dos países do $1^{\circ}$ Mundo tem como pré-condição investimentos maciços em educação. Tais investimentos devem ter, basicamente, os seguintes objetivos: alfabetização total da população, melhor qualificação dos quadros docentes, ampliação dos anos de escolaridade, extensão do tempo de permanência na escola, ampliação dos programas de $2^{\circ}$ e $3^{\circ}$ graus, melhoria da qualidade do ensino, elevação dos níveis culturais da população etc. Sabendo-se que muitos começam a trabalhar em idade precoce, sem uma formação adequada, é notória a desvantagem do Brasil com relação às nações do primeiro mundo e às nações asiáticas emergentes, em termos de anos de escolaridade e, particularmente, em termos de qualidade dessa educação.

Embora muito progresso venha sendo alardeado em anos recentes, evidenciado por diversos indicadores, como a crescente universalização da educação, maior permanência na escola, progressiva demanda pelos níveis superiores etc, ainda persistem óbvios problemas em extensas áreas rurais de determinados estados do país, como também em todas as áreas periféricas ou favelizadas das grandes metrópoles. As grandes regiões metropolitanas foram atingidas por intensos processos migratórios durante as décadas de 50 a 80 e uma boa parte de tais contingentes integrou-se marginalmente à sociedade local, deixando exposta uma significativa ruptura social, econômica e cultural que muito afeta a propensão à educação e dificulta a própria ação da escola. A superação desse retardo constitui-se um notável desafio para o país.

Um dos importantes problemas que afeta a rede escolar é a sua distribuição espacial, após várias décadas de expansão populacional, de migração desordenada, de intensa urbanização, de favelização explosiva e outras fraturas demográficas. Uma conseqüência desse crescimento populacional explosivo nos grandes centros, e em suas respectivas regiões metropolitanas, foi a inépcia do poder público em acompanhar adequadamente a demanda ampliada e mutante. Quanto à oferta de ensino, entretanto, a realidade hoje parece menos grave, diante da forte redução das taxas de natalidade, da exaustão dos processos migratórios internos e dos sistemáticos investimentos em educação realizados no país. Desse modo, faz sentido o estudo da localização das escolas e a subseqüente busca da otimização espacial da rede, especialmente nas grandes áreas urbanas e em suas regiões metropolitanas.

Estudos de localização de escolas são conduzidos regularmente em vários países, tanto em áreas rurais como urbanas, por razões diversas. Para países que enfrentam forte redução nas taxas de nascimento, o problema consiste em escolher as escolas a serem fechadas. Outros países enfrentam o problema oposto de altas taxas de natalidade associadas à mobilidade da população, o que exige uma reavaliação periódica da rede escolar. Em sociedades em desenvolvimento, o esforço pela modernização exige igualmente a expansão do sistema educacional para setores da sociedade antes ignorados, como costuma ser o caso das populações rurais ou de populações recentemente absorvidas pela urbe.

O modelo usual para estudos de localização de escolas é o modelo da p-mediana, discutido mais adiante. Esse modelo é apropriado para áreas urbanas e densamente povoadas; ele pressupõe que o aluno prefere a escola mais próxima de sua residência. De acordo com esse modelo, a localização ideal das escolas corresponde a centros de gravidade que minimizem a distância residência-escola, a qual é percorrida duas vezes por dia. Em áreas rurais o mesmo 
princípio é válido, mas as grandes distâncias e as esparsas populações exigem outros tipos de modelagem. O MEC divulgou recentemente a auspiciosa informação que já chegam a 4 milhões os alunos de áreas rurais no Brasil que usam o transporte municipal para alcançarem suas escolas. Isso é resultado de programas federais de financiamento ao transporte escolar que eliminam a micro escola rural, constituída por turmas multi-seriadas, e conduzem os alunos a escolas regulares e nucleadas em áreas mais povoadas e próximas às sedes dos respectivos municípios e de seus distritos.

Molinero (1988) examinou a localização de escolas em Southampton, Inglaterra, originalmente colocadas no centro de áreas definidas por zoneamentos geográficos. A redução das taxas de natalidade desencadeou o problema de fechamento de escolas. Entretanto, a queda das taxas de natalidade não foi uniforme por todas as classes sociais. $\mathrm{O}$ autor destacou os objetivos conflitantes entre a administração pública, preocupada com custos, e a comunidade, preocupada com a qualidade do serviço. Tewari \& Jena (1987) consideraram a localização de escolas secundárias em áreas rurais da Índia. Eles aplicaram o modelo da p-mediana e propuseram localizações que maximizam a população coberta dentro de um distância máxima de $8 \mathrm{~km}$, supondo que o aluno do nível secundário esteja apto a largos deslocamentos diários.

Antunes (1994) estudou a rede escolar no centro oeste de Portugal e aplicou métodos de programação matemática, também com base no modelo da p-mediana. Viegas (1987) usou um algoritmo de fluxo em redes para selecionar os locais mais econômicos para construir ou expandir uma escola, de modo a limitar a distância máxima de acesso a uma escola, notando que a redução de tal distância exige mais escolas e mais custos. Tewari (1992) examinou o acesso a serviços públicos nas áreas rurais e contrasta o uso de modelos de pesquisa operacional com os conceitos de desenvolvimento rural propostos pela USAID nos anos 70 . Armstrong et alii (1990) desenvolveram um sistema para fornecer suporte aos decisores que localizam postos de serviços. Stock (1983) examinou aplicação semelhante, mas direcionada a postos de saúde. Estudos relacionados à localização de escolas também podem ser encontrados em Rahman \& Smith (1991), ReVelle \& Swain (1970), Banerji \& Fisher (1974), Fisher \& Rushton (1975) e Beguin et alii (1989).

Com relação a estudos feitos no Brasil, levantamento incompleto aponta Silva (1991), Silva (1995), Pizzolato \& Silva (1993), Pizzolato \& Silva (1997), Dutra (1998), Barros (2000) e Barcelos (2002). Dentre estudos análogos, com respeito à localização de centros de assistência maternal e perinatal no Rio de Janeiro/RJ destaca-se Vasconcellos (1997) e, ainda, Galvão et alii (2002) que ampliaram o estudo de localização de maternidades propondo o uso do modelo da p-mediana na forma hierarquizada em três níveis, em função do atendimento especializado.

O objetivo deste artigo é divulgar em nosso ambiente diversas experiências que têm sido realizadas pelos autores na área de localização de escolas, assim como colocar em periódico brasileiro o conhecimento desenvolvido localmente, mas cuja divulgação tem privilegiado os veículos internacionais ou ficado restrito a estantes acadêmicas. Em particular, é examinada evolução da metodologia que, no início, exigia mapas em papel com os setores censitários devidamente marcados. Tais mapas não são mais produzidos, passando-se a usar mapas digitalizados e usar sistemas de informação geográficos para seu processamento. Ao trocar um sistema por outro há vantagens e desvantagens em jogo, mas o uso extenso da computação gráfica é um caminho sem retorno, devendo-se mais explorar suas vantagens do que lamentar as eventuais desvantagens. 
O trabalho está apresentado da seguinte forma: na Seção 2 é explicada a metodologia que vem sendo adotada a qual está dividida em duas fases: (1) avaliação da atual localização e (2) proposta de relocalização. A Seção 3 relata importantes estudos feitos em algumas áreas urbanas brasileiras, organizadas historicamente, de modo a destacar a evolução metodológica, a saber: Nova Iguaçu, Nilópolis, Niterói, Ilha do Governador e Fortaleza. A Seção 4 sintetiza conclusões.

\section{Metodologia Básica de Localização}

Estudos de localização de escolas exigem o conhecimento da distribuição geográfica da população. Essa distribuição é tipicamente anárquica, pois depende de padrões urbanísticos e condicionantes econômicos, culturais, políticos e topográficos reinantes em cada região. Para facilitar estudos analíticos, a simplificação mais freqüente consiste em discretizar a população de acordo com os setores censitários, que são pequenas unidades geográficas definidas pelo IBGE, responsável pelo Censo Demográfico. Em áreas urbanas, cada setor consiste em aproximadamente 300 residências, de modo que um único recenseador consiga visitá-las e coletar as informações. Para cada setor, dados sociais e demográficos são divulgados, incluindo a pirâmide etária, padrões de educação familiar, níveis de renda, qualidade da habitação e diversos outros indicadores sociais e econômicos. De acordo com o processo de digitalização em marcha, o IBGE vem oferecendo os mapas dos principais municípios brasileiros, acrescido dos contornos de cada setor censitário.

A seguir, cada setor censitário é substituído por um vértice, geograficamente próximo ao seu geocentro, ou centróide. Esse vértice representa o ponto que concentra toda a população do setor censitário. Afastamentos entre geocentros devem ser medidos mediante distâncias euclideanas ou mediante distâncias ao longo dos percursos possíveis entre os pares de vértices. Assim, cria-se um grafo $G=(N, A)$, com $N=\{1, \ldots, n\}$ vértices, representando os geocentros dos setores censitários da área em estudo. Para cada vértice $i \in \mathrm{N}$ está associado um peso $q_{i}$, o qual representa a sua população escolarizável ou demanda escolar centrada naquele vértice e a cada par de vértices $(i, j)$ está associada uma distância $d_{i j}$. A matriz $\mathrm{D}=\left[\mathrm{d}_{\mathrm{ij}}\right]$ reúne as distâncias entre todos os pares de vértices.

Elemento básico da análise é a área de influência de cada escola. Essas áreas podem ser determinadas por diversos métodos, como os círculos concêntricos, que seriam os mais intuitivos, o diagrama de Voronoi, o método da bolha, que corresponderia aos círculos concêntricos, mas sem interseções, a p-mediana e assim por diante. Sem dúvida, o sistema mais popular é o modelo da p-mediana, que se baseia no critério de menor distância e simboliza o deslocamento do aluno até a escola mais próxima.

O modelo da p-mediana supõe que tanto alunos como escolas estejam localizados nos vértices, e que os alunos preferem a escola mais próxima de suas residências. Dessa forma, se um vértice contém uma escola ela atende todo aluno que mora naquele setor censitário, o qual, de acordo com a simplificação adotada, percorrerá uma distância nula. Caso o vértice não contenha uma escola, o morador vai preferir o vértice mais próximo com uma escola e todos os alunos percorrerão a distância separando esses dois vértices. Essa simplificação é considerada razoável, pois as distâncias entre vértices aproximam a distância média para o conjunto de alunos dispersos em um setor censitário, caminhando para o geocentro de um setor vizinho. Além disso, essa hipótese guarda coerência com o comportamento real, que leva o aluno a deslocar-se a pé para a escola mais próxima. Nos municípios onde existe o 
planejamento centralizado da matrícula, a alocação de alunos segue exatamente o critério da proximidade. Tal critério não se aplica quando as escolas em confronto possuem aspectos distintivos tais como tradição, qualidade das instalações e do ensino oferecido, oportunidades de acesso a séries superiores, alternativas diferenciadas de ensino, contradições culturais ou sócio-econômicas etc.

$\mathrm{O}$ uso do modelo da p-mediana pode ser visto como o problema de tomar os $\mathrm{N}$ vértices e agrupá-los em $p$ conjuntos, em torno de um vértice mediano, onde existe ou deveria existir uma escola. Esse processo produz $p$ micro regiões, $C_{1}, C_{2}, \ldots, C_{p}$, cujas respectivas medianas são as localizações e cada um dos demais vértices do grafo pertence a uma das regiões cuja mediana seja a mais próxima. Esse critério corresponde à idéia intuitiva que o aluno se dirige à escola mais próxima de sua residência. A experiência sugere que essa hipótese é verdadeira no momento em que as escolas da rede pública tenham igual atratividade e será menos realista quando as escolas forem heterogêneas, tanto no que se refere à qualidade do ensino e instalações, como quanto a estratos sociais atendidos e demais fatores acima citados. $\mathrm{O}$ modelo da p-mediana, ou problema PPM, corresponde ao seguinte modelo de programação linear binária:

$$
\begin{aligned}
& \text { Min } \sum_{i=1}^{n} \sum_{j=1}^{n} q_{i} d_{i j} x_{i j} \\
& \text { sujeito } a \quad \sum_{i=1}^{n} x_{i j}=1 ; j \in N \\
& \sum_{j=1}^{n} x_{j j}=p \\
& x_{i j} \leq x_{j j} ; i, j \in N \\
& x_{i j} \in\{0,1\} ; i, j \in N
\end{aligned}
$$

onde:

$\mathrm{N}$ é o conjunto de vértices da rede, $\mathrm{N}=\{1, \ldots, \mathrm{n}\}$;

$\mathrm{D}=\left[\mathrm{d}_{\mathrm{ij}}\right]_{\text {nxn }}$ é a matriz simétrica de distâncias, $\operatorname{com} \mathrm{d}_{i i}=0, \mathrm{i} \in \mathrm{N}$;

$p$ é o número de medianas a serem localizadas;

$\mathrm{q}_{i}$ representa a população escolar do vértice $i$

$x_{i j}$ são as variáveis de decisão, com $x_{i j}=1$ se o vértice $i$ está alocado ao vértice $j$, e $x_{i j}=0$, no caso contrário; e $x_{j j}=1$ se o vértice $j$ é uma mediana e $x_{j j}=0$, no caso contrário, para $i, j \in N$

A função objetivo consiste em minimizar as distâncias ponderadas de cada vértice à mediana mais próxima; as restrições (1) e (3) impõem que cada vértice $i$ seja alocado a um único vértice $j$, o qual deve ser uma mediana. A restrição (2) determina o exato número $p$ de medianas a serem localizadas e (4) indica as condições de integralidade.

A experiência tem mostrado que estudos sobre localização de escolas devem ser decompostos em duas fases, a saber:

1) Avaliação da localização atual; e

2) Proposta da localização ideal ou ótima. 
A primeira fase, avaliação da localização atual, consiste basicamente em tomar as escolas em suas localizações atuais, e identificar suas respectivas áreas de atração, ou seja, as áreas em que, pelo critério de proximidade, seriam atendidos por cada escola. Com isso, e conhecida a presente capacidade de cada escola, pode-se comparar a demanda de sua zona de atração com esta capacidade. Desse modo, é possível identificar aquelas escolas que deveriam ser maiores e aquelas que poderiam ser menores. Esse procedimento é notavelmente auto explicativo, para identificar zonas com escassez de vagas e zonas com excesso de vagas. Basta que as áreas com desequilíbrios sejam representados em um mapa, de acordo com um código de cores que aponte as gravidades dos desequilíbrios, ou as regiões mais críticas, tanto no sentido do excesso de capacidade como no sentido oposto.

Quanto aos desequilíbrios, sabe-se que a capacidade de uma escola pode ser largamente ajustada, seja pela ampliação de turmas, seja pela adoção de mais um turno, seja pelo aproveitamento de salas não usadas, seja por pequenas obras de ampliação etc. A redução de capacidade, evidentemente, é algo mais simples, bastando cancelar turmas e relocalizar professores e equipamento escolar. Trata-se de um argumento importante para justificar o uso do modelo não capacitado, como apresentado acima, em lugar do modelo capacitado que exige maior esforço computacional e sobre o qual os avanços metodológicos são incipientes.

Certamente, os resultados alcançados devem ser interpretados como normativos e, para passar à fase de implementação, essa informação deve ser confrontada com a demanda efetiva observada por cada escola, pois em áreas habitadas pela classe média a demanda pela escola pública tende a ser muito inferior à população escolar. Importante ressaltar que essa última regra é bem nítida nos grandes centros urbanos e suas regiões metropolitanas, mas não é verificada nas cidades menores do interior, onde as melhores escolas públicas continuam a gozar de grande prestígio.

Quanto à segunda parte do estudo, a localização ideal ou ótima, ela é obtida pela solução do modelo da p-mediana acima estabelecido. Pela intuição de muitos esse estudo não faria sentido, pois as escolas existentes não seriam fisicamente removíveis. Entretanto, a experiência sugere que, além do interesse acadêmico, o estudo da localização ótima justificase quando os desequilíbrios são graves ou quando há uma necessidade suplementar de construir-se novas escolas. Naturalmente, o estudo permite diagnosticar se os desequilíbrios são ou não importantes e em que sub regiões eles mais se manifestam.

Cabe ressaltar que, para efeitos gerenciais, a proposta de relocalização inclui procedimentos para conciliá-la com a rede existente, não ignorando as escolas já existentes, com seus terrenos e instalações. Esse procedimento de conciliação da rede existente com a rede proposta se passa da seguinte forma: a localização ideal de cada escola produz uma zona de abrangência, ou uma micro região de atendimento. Algumas dessas micro regiões podem já conter uma ou mais escolas com capacidades conhecidas, sugerindo que a capacidade conjunta seja entendida como a capacidade já instalada naquela micro região. A partir daí, o mesmo código de cores pode ser usado para representar as áreas com escassez ou com excesso de vagas.

Com as considerações acima, a metodologia desenvolvida, incluindo a fase de avaliação da rede atual e a fase de proposta de localização é constituída por seis passos. Esses estão descritos abaixo e, logo após, sucedidos por comentários decorrentes de seu uso prático. 


\section{A Metodologia}

PASSO 1: Os Vértices da Rede

Marcar os geocentros, ou pontos centrais da cada setor censitário correspondente os quais, para efeitos do estudo, contêm toda a população escolarizável deste setor, ou seja, na faixa 7 a 14 anos;

PASSO 2: Os Arcos da Rede e a Matriz de Distâncias

Determinar as distâncias entre os geocentros determinados no passo anterior e formar a matriz de distâncias;

PASSO 3: Avaliação da Localização Atual

No caso de um estudo de avaliação da situação atual, há que identificar quais setores censitários possuem atualmente escolas, supô-las localizadas em seus respectivos geocentros e seguir ao Passo 5;

PASSO 4: A Localização Proposta

Na fase de localização ideal, o modelo da p-mediana deve ser aplicado, usandose métodos exatos ou heurísticos, de modo a obter uma proposta de zoneamento escolar baseada em localizações ótimas.

PASSO 5: Interpretação e Apresentação dos Resultados A partir das escolas localizadas, sejam as existentes (Passo 3), sejam as propostas (Passo 4), determina-se as respectivas áreas de atração, de acordo com a proximidade A demanda resultante deve ser comparada com a capacidade da escola correspondente.

PASSO 6: A Validação dos Dados:

A implementação das medidas sugeridas pelo estudo passa antes pela validação dos dados usados e pelas conclusões alcançadas. Em particular, as regiões com maiores discrepâncias devem ser visitadas e as anormalidades investigadas.

\section{Comentários Sobre a Metodologia}

Algumas observações sobre cada um dos passos acima podem ser relevantes. Assim, o Passo 1 considera a população escolarizável na faixa 7-14 anos, que corresponderia ao ensino fundamental, para o qual estados e municípios são obrigados a oferecer vagas e impor o comparecimento. Cabe acrescentar diversos condicionantes que afetam esse número, tais como: i) a presença do ensino privado que atrai parcelas de alunos da classe média e alta, absorvendo, tipicamente, cerca de $30 \%$ da população escolar; ii) a presença de alunos fora da faixa 7-14 no estudo fundamental, alguns poucos por início ou conclusão precoces e muitos, cujo porcentual pode alcançar $30 \%$, por repetência, evasão etc, levando-os a se encontrarem no sistema fundamental após os 14 anos; iii) a chamada meta de escolarização é um fator do tipo $95 \%$ ou um pouco menos, correspondendo à população que efetivamente dirige-se à escola, o restante ficando por conta de alunos especiais, cujo atendimento exige escolas distintas da rede regular, e as demais diante de perdas por evasão, abandono ou outras.

O Passo 2 pede a medição de distâncias entre os geocentros. Como explicado nas aplicações descritas na Seção 3, a forma de medir distâncias sofreu modificações progressivas. No primeiro estudo, descrito na Seção 3.1, foram utilizadas distâncias reais, medidas ao longo das vias, mas esta opção revelou-se extremamente trabalhosa. Em estudos posteriores foram usadas distâncias euclideanas entre pares vizinhos de vértices e, a partir daí, com as 
distâncias de um vértice aos seus vizinhos mais próximos, o algoritmo de Floyd e Warshall (Lawler, 1976) permite completar a matriz completa entre todos os pares de vértices. Com o uso dos sistemas geográficos, pode-se redigir uma rotina para medir as distâncias euclideanas entre todos os pares de vértices e preencher a matriz de distâncias.

O Passo 3 pode ser visto como a aplicação do modelo PPM na situação particular em que os valores $x_{j j}$ já são conhecidos a priori, nada havendo a otimizar. A resolução do modelo, com uma função objetivo arbitrária, vai limitar-se a produzir uma solução viável, ou seja, a matriz de alocação $\left[x_{i j}\right]$ que aponta as micro regiões alcançadas por cada escola. Se o Passo 3 for executado por um algoritmo de alocação, em que cada vértice é alocado à escola mais próxima, tem-se, de modo simples, a construção das micro regiões.

Para o Passo 4 existem métodos exatos ou heurísticos. A limitação dos métodos exatos, decorrente do tamanho e exigências computacionais para resolver o problema binário PPM, vem sendo progressivamente superada com a oferta de métodos mais avançados e de recursos computacionais cada vez mais sofisticados. Dentre muitas propostas de resolução, Galvão \& Raggi (1989) tem se constituído em uma referência importante na obtenção da solução exata. Os métodos heurísticos para o modelo da p-mediana não capacitado têm uma vantagem prática decorrente de sua programação mais simples, intuitiva e artesanal, podendo incorporar preferências, como o efeito de uma localização nova, a manutenção de uma localização específica e outras flexibilidades, contrastando com o método exato que produz uma solução única e ótima, sem outros qualificativos. Existem muitos métodos heurísticos propostos, mas os presentes trabalhos usaram a metodologia sugerida por Pizzolato (1994).

No Passo 5, o zoneamento resultante deve ser colocado em um mapa para efeitos de apresentação. Além disso, os desequilíbrios entre a capacidade da escola existente em cada micro região (Passo 3), ou a capacidade das escolas eventualmente existentes (Passo 4), e a população existente nos centróides da respectiva área de influência, determinam os desequilíbrios, que serão de interesse para o planejamento. Esses desequilíbrios devem ser apresentados em mapas coloridos segundo sua gravidade.

No Passo 6 há que examinar localmente as discrepâncias diversas encontradas. Essas normalmente são resultado de desequilíbrios efetivos, mas podem ser resultado de erros de dados de alimentação do modelo. Há que considerar aqui a presença das escolas particulares, que costumam atender segmentos importantes da população, normalmente concentrados em áreas específicas da cidade.

Na seqüência, estão descritos cinco trabalhos desenvolvidos, em ordem cronológica. Todos esses estudos usaram a p-mediana, um algoritmo heurístico e atingiram importantes cidades. Entretanto, eles diferem em diversos aspectos, desde a forma de coletar dados, até a evolução de mapas em papel para mapas digitalizados. São eles: Nova Iguaçu, Nilópolis, Niterói, Ilha do Governador e Fortaleza.

\section{Síntese de Cinco Trabalhos Realizados}

\subsection{Nova Iguaçu/RJ}

O primeiro trabalho de grande envergadura ocorreu no $1^{\circ}$ Distrito de Nova Iguaçu/RJ e encontra-se descrito em Silva (1991) e em Pizzolato \& Silva (1993). Pelo seu significado histórico e em razão de suas especificidades, ele será aqui brevemente revisto. 
Nova Iguaçu integra a Região Metropolitana do Rio de Janeiro, onde se estima que cerca de cinco milhões de pessoas tenham se estabelecido entre as décadas de 50 a 80 e, em conseqüência, desorganizado qualquer sistema de atendimento público. Problemas característicos dessa região incluem: crescimento demográfico explosivo, com migrações internas que atingiram taxas superiores a $7 \%$ a.a. nas décadas de 50 a 60 ; cerca de $4,1 \%$ a.a. na década de 70 e 1,48\% a.a. na década de 80 . Em passado recente, era rotulada como cidade-dormitório, carecendo de identidade entre governo e população, baixos níveis de cidadania e participação, administração pública clientelista e fisiológica, sem compromissos com as necessidades de sua população. No caso do sistema educacional, havia a suspeita, ao final da década de 70, da existência de milhares de jovens fora da escola.

O quadro acima começou a sofrer forte mutação a partir da redemocratização ocorrida na década de 80, estimulada pela concentração eleitoral na denominada Baixada Fluminense, cujo epicentro estava exatamente em Nova Iguaçu. Essa nova força política passou a impor tanto ao Estado como aos municípios locais a priorização de investimentos públicos. É até possível que a íntegra do presente estudo, divulgado localmente, tenha contribuído para a melhoria da rede de ensino local.

O estudo abordou o $1^{\underline{0}}$ distrito do município, correspondendo a uma população de quase 500.000 habitantes em 1980, divididos em 389 setores censitários e 94 escolas públicas, algumas muito pequenas e muitas vizinhas de outras, de modo que foram supostas 85 escolas distintas, com capacidades conhecidas, porém com grau extremo de heterogeneidade quanto ao tamanho, qualidade, conservação etc. $\mathrm{O}$ estudo seguiu precisamente a metodologia proposta na seção anterior, com a execução das duas fases. Os casos extremos de carência e excesso foram objeto explícito de análise, a título de validação. Essa validação aproveitou sondagem independente feita na oportunidade com todas as escolas da rede estadual do município a qual incluía uma pergunta sobre a disponibilidade de vagas. As respostas claramente validaram o comportamento do aluno de acordo com o modelo da p-mediana, exceto diante de escolas com algum fator distintivo, que a tornava atraente para o aluno, prevalecendo sobre o critério distância.

A grande surpresa do estudo foi encontrar regiões com excesso de vagas, pois o consenso geral era que o município como um todo possuía uma enorme escassez. Com respeito às escolas estaduais situadas em regiões em que o estudo apontou excesso de vagas, a sondagem apontava, igualmente, que várias destas escolas informavam possuir, efetivamente, vagas disponíveis em diversas ou quase todas as séries do $1^{\mathrm{o}}$ grau, convalidando a premissa do modelo. De certo, algumas declararam não possuir vagas ociosas, mas eram escolas dotadas de especificidades além do critério distância, como foi o caso de um instituto de educação, de uma escola dotada do $2^{\circ}$ grau e de outra escola muito pequena e atraente.

\subsection{Nilópolis/RJ}

O estudo de Nilópolis é, certamente, o mais didático, em que todas os passos e fases da metodologia foram aplicados os quais, pelas dimensões e características urbanas, conseguem ser representados em três figuras. Trata-se de um pequeno município da região metropolitana do Rio de Janeiro, com cerca de $10 \mathrm{~km}^{2}$. De acordo com o Censo de 1991, sua população era de 157.936, com uma proporção de jovens na idade 7-14 anos de 18,5\% sobre a população total. Por suas características unicamente urbanas, preponderando residências e sem prédios 
altos, Nilópolis forma um ambiente propício a estudos sócio-urbanísticos. A Figura 1 mostra o mapa de município dividido em 135 setores, reduzidos no estudo a 128, em razão de alguns representarem penitenciárias, instalações militares, hospitais, hotéis etc. As 23 bolinhas pretas representam a localização das 23 escolas públicas existentes na época do estudo, reduzidas a 22 em razão de haver duas vizinhas entre si, no setor número 73, desempenhando o papel de uma única com capacidade combinada.

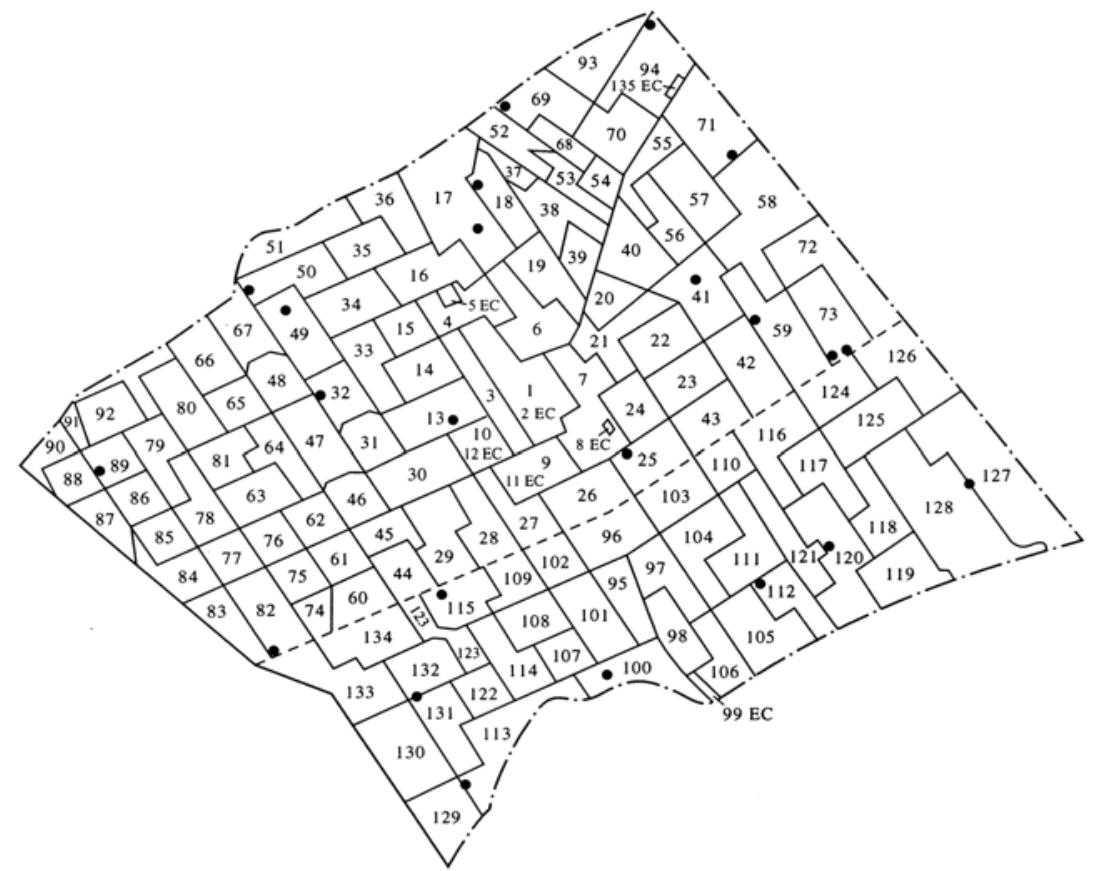

Figura 1 - Nilópolis - Setores Censitários e Localização das Escolas Públicas do Ensino Fundamental, 1991

Os geocentros não estão indicados, mas foram marcados próximos aos centros geométricos de cada setor. Algumas poucas distâncias entre vértices foram medidas em termos euclideanos, enquanto que a matriz de distância foi encontrada pelo método de Floyd e Warshall (Lawler, 1976).

A seguir, foi feita a primeira parte do estudo, qual seja, a avaliação da situação atual, correspondendo aos Passos 3 e 5 da metodologia. Para tanto, foram identificados os 22 setores contendo escolas e, para todo outro vértice, verificada qual a escola mais próxima. Para cada uma das árvores, a população escolar total, o nome da escola, sua capacidade por série etc., pode ser registrada e indicada como desejado. Assim, confrontando oferta e demanda, os desequilíbrios podem ser calculados e exibidos por meio de visualização gráfica. A Figura 2 mostra os resultados. A ausência de cores torna a apresentação menos clara, e exige esforço na interpretação. Os contornos (imperfeitamente visíveis) delimitam as 22 micro regiões ao redor das escolas existentes (bolinhas pretas). Quando as áreas delimitadas são brancas, há um excesso ou escassez de vagas de até 500 vagas. Nas áreas cobertas com quadriculado (caso dos setores 126, 72 e 73) há um excesso de oferta de mais 
de 1.000 vagas. Nas regiões cobertas com pontilhado (setores 113 e 122) o excesso está entre 500 e 1.000. Nas micro regiões escurecidas a escassez é de 500-1.000 vagas, enquanto que nas áreas tracejadas a escassez é superior a 1.000 vagas por escola.

A Figura 2 sugere duas importantes conclusões para o gerenciamento do sistema no curto prazo. Uma é que os maiores desequilíbrios estão claramente na região oeste do município. Portanto, qualquer nova construção ou expansão deve priorizar essa região. Outro aspecto é o gerenciamento da capacidade. Muito possivelmente, as quatro escolas na região oeste podem, mediante medidas emergenciais, expandir-se com a construção de salas adicionais, aproveitamento de espaços vazios etc. Em paralelo, as escolas com excesso de vagas podem ceder professores e equipamento escolar, como carteiras, quadros negros, pessoal auxiliar etc.

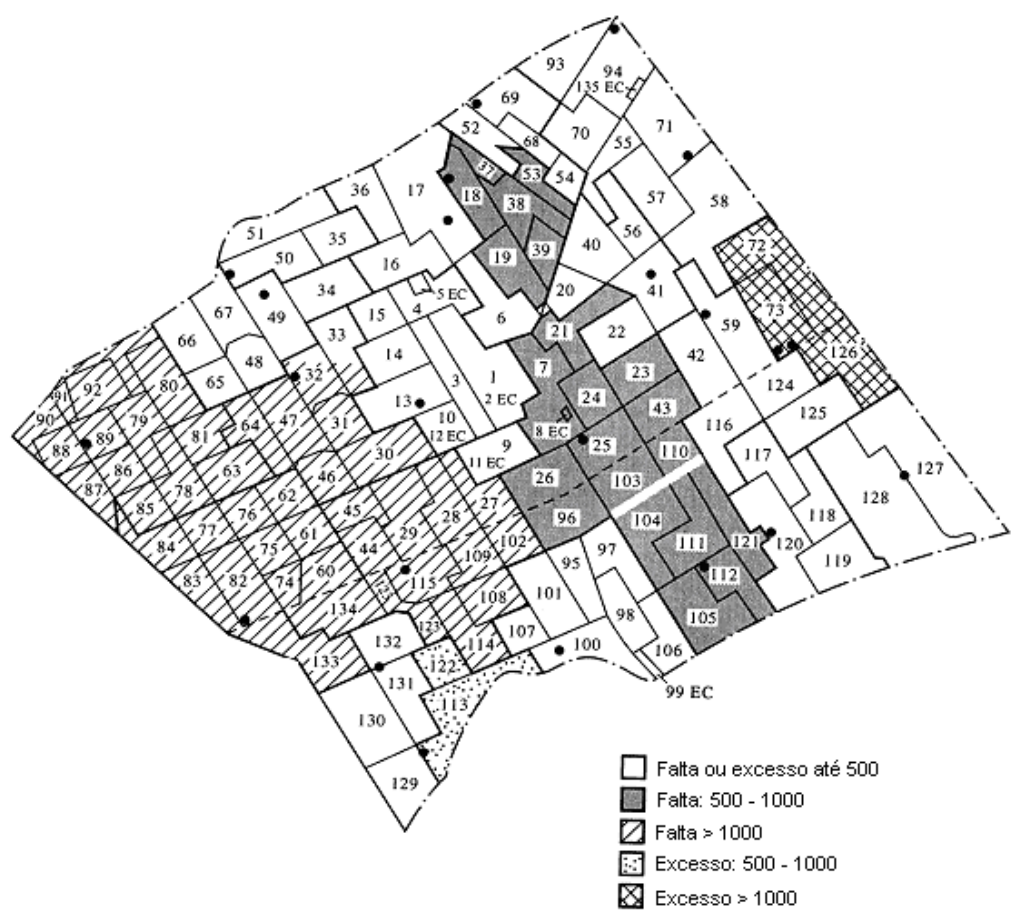

Figura 2 - Nilópolis - Avaliação da Atual Localização das Escolas, 1991

A localização ideal está indicada na Figura 3, resultado da aplicação dos Passos 4 e 5 da metodologia. Ela foi obtida com apoio de solução heurística do modelo da p-mediana, usando $\mathrm{p}=22$. Nesse ponto foi incorporado ao modelo a condição de capacidade de cada escola. Para tanto, foi entendido que a solução do modelo oferece 22 micro regiões, formando um zoneamento escolar proposto. Naturalmente, em algumas dessas micro regiões já existe uma ou mais escolas, com capacidades conhecidas. Portanto, para cada micro região, existe uma população escolarizável e uma oferta de vagas, cuja diferença vai determinar o excesso ou escassez de vagas nas referidas micro regiões. A Figura 3 indica os resultados alcançados, com convenção de cores similar à figura anterior. Idealmente, deve haver uma escola no centro de cada micro região, mas como as áreas em estudo são relativamente pequenas, julga-se que qualquer escola na área desempenha o mesmo papel. 
Fato peculiar na Figura 3 é a micro região composta pelos setores 42, 59, 72 e 73 já possuírem três escolas, duas das quais muito grandes, gerando um significativo excedente de vagas. Certamente, a Figura 3 torna-se relevante para o longo prazo, apontando para transferências de capacidade.

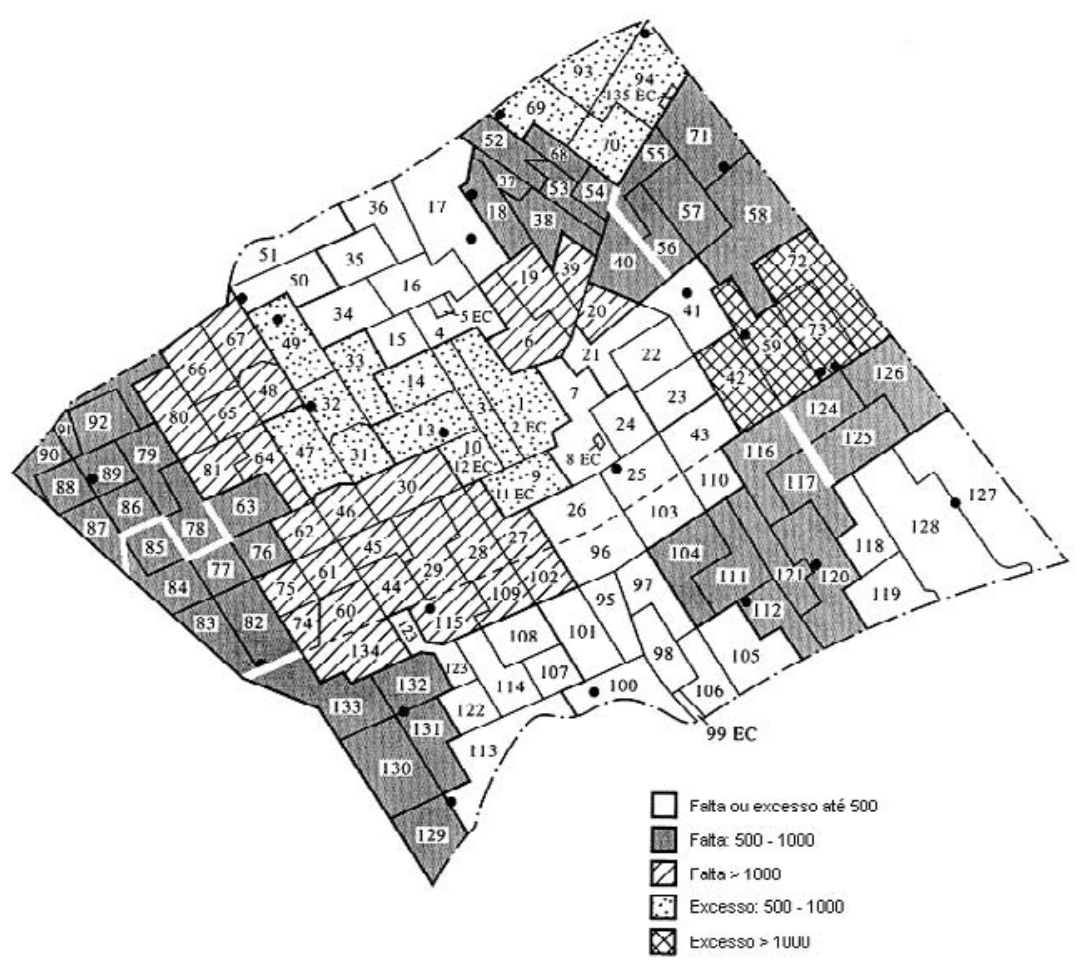

Figura 3 - Nilópolis - Localização proposta das escolas públicas, 1991

\subsection{Niterói/RJ}

A cidade de Niterói/RJ possuía uma população de 450.364 habitantes, de acordo com o Censo de 1996. Como capital do antigo Estado do Rio de Janeiro, redefinido em 1965 com a fusão com a cidade de mesmo nome, Niterói possui uma tradição cultural que a levou a ser uma das cidades brasileiras de melhor qualidade de vida e a de maior nível de renda dentro dos limites do Estado do Rio de Janeiro. Influenciado por esses fatores, a rede particular chegou a atender uma proporção extraordinária de quase $50 \%$ de alunos, porcentual este reduzido ao longo da década de 90, paulatinamente, para 35\% em 1996. Essa redução costuma ser atribuída tanto à melhoria das condições de ensino na escola publica como ao chamado empobrecimento da classe média.

O estudo desenvolvido encontra-se disponível em Silva (1995) e em Pizzolato et alii (1999) e avaliou o problema da capacidade do sistema e sua distribuição espacial. A primeira parte do estudo foi motivada pela surpresa em encontrar uma população escolar bastante superior à população demográfica, sugerindo, à primeira vista, erros no Censo ou erros nos dados escolares. Entretanto, avaliação mais abrangente, incluindo levantamentos junto às escolas, 
identificou uma outra origem no problema, qual seja, a migração de alunos de outros municípios. Com isso, foi proposto um modelo para avaliar a capacidade da rede escolar, que pode ser útil para qualquer diagnóstico destinado ao planejamento da rede, bem como anteceder estudos de localização.

Avaliar a capacidade de rede escolar consiste em comparar a demanda com a oferta. Na expressão a seguir, entende-se que o Ensino Fundamental (EF), abrangendo da $1^{\mathrm{a}}$ à $8^{\mathrm{a}}$ série, deve ser idealmente realizado entre os 7 e os 14 anos. O EF pode ser precedido tanto pela Classe de Alfabetização (CA), de existência desejável, mas não obrigatória, como pelo Pré-escolar (PE), onde se inicia o processo de integração à escola. A meta de escolarização é um porcentual que exclui a parcela da população que não freqüenta a escola regular devido a fatores diversos, tais como a frequiência a escolas especiais, a impossibilidade de estudar, o desejo de simplesmente não estudar etc. A expressão proposta abaixo compara demanda com oferta, supondo que o compromisso público seja a garantia de vagas no EF àqueles na faixa 7-14 anos.

Demanda $=$ População escolar na faixa 7-14 anos

(-) Meta de não escolarização

Oferta $=$ Matrículas totais no EF

(-) Matrículas no EF com $<7$ anos

(-) Matrículas no EF com $>14$ anos

(-) Concluintes do EF com $<15$ anos

(+) Matrículas na CA e no PE com $>6$ anos

A expressão acima é importante para o planejamento escolar, tendo um caráter normativo. Ela parte da descrição atual do sistema, que constrange a oferta pela ineficiência série-idade, refletida no numeroso contingente acima de 15 anos ainda no sistema, embora aliviada pela ausência dos acima de 6, demandantes, entretanto, de outros recursos dos sistemas de ensino, e também pelos concluintes precoces, abaixo dos 15 anos, que deixaram o sistema por conclusão do ciclo de estudos. A expressão anterior foi avaliada com os dados referentes a Niterói, e também ampliada aos municípios vizinhos de São Gonçalo e Itaboraí, tendo gerado a Tabela 1.

Tabela 1 - Demonstrativo de Excesso ou Escassez de Escolaridade na Rede de Ensino em Três Municípios do Rio de Janeiro, 1996

\begin{tabular}{c|r|r|r}
\hline Tipo & Niterói & \multicolumn{1}{c|}{ São Gonçalo } & \multicolumn{1}{c}{ Itaboraí } \\
\hline \hline Matriculados no Ensino Fundamental & 70.572 & 122.487 & 31.202 \\
\hline (-) Alunos com menos de 7 anos & $(281)$ & $(292)$ & $(17)$ \\
\hline (-) Alunos com mais de 14 anos & $(12.753)$ & $(27.820)$ & $(7.666)$ \\
\hline Matriculados CA com mais de 6 anos & 4.024 & 7.556 & 3.662 \\
\hline Matriculados PE com mais de 6 anos & 270 & 207 & 150 \\
\hline Fundamental Concluído (estimativa) & $\underline{441}$ & $\underline{742}$ & $\underline{23}$ \\
\hline$=$ Matriculados ou formados: 7-14 Anos & 62.273 & 102.880 & 27.354 \\
\hline População: Censo Demográfico & 55.284 & 117.805 & 25.516 \\
\hline (-) Ajuste Meta de Escolaridade (3\%) & $(1.658)$ & $(3.534)$ & $(765)$ \\
\hline$=$ Demanda Escolar & 53.626 & 114.271 & 24.751 \\
\hline = Excesso (Escassez) de Vagas Públicas & $\underline{\underline{8.647}}$ & $\underline{(11.391)}$ & $\underline{\underline{2.603}}$ \\
\hline
\end{tabular}


A interpretação dos resultados da Tabela 1 não é muito simples. Por um lado, pode-se dizer que o poder público oferece em Niterói 70.572 - 53.626 = 16.946 vagas além da população a ser atendida,de acordo com o recenseamento, o que parece extraordinário. Entretanto, existe um vasto alunado atrasado na sua educação,ocupando boa parte das vagas, além de outros ajustes nos dados, que justificam a análise da Tabela 1 .

Uma outra interpretação seria a seguinte: Niterói oferecia, em 1996, 8.647 vagas além de sua população de 7-14 anos e, ao se somar a população não demandante do sistema publico, cerca de 24.961 alunos do ensino fundamental da rede privada, no mesmo ano, conclui-se que a oferta é altamente satisfatória. Entretanto, a demanda pelo sistema público é fortemente ampliada pela distorção série-idade e pela migração de alunos dos municípios vizinhos não tão bem equipados. Esse último número não é de fácil identificação, exigindo amostragens ou levantamentos junto às escolas. A título de exemplo, em uma das escolas visitadas, situada próximo à rodoviária da cidade, a direção estima que $30 \%$ de seu corpo discente provém dos municípios vizinhos.

Quanto à distribuição espacial das escolas, a avaliação do estudo resultou em um diagnóstico muito favorável, mas recomendando cuidadoso acompanhamento gerencial, decorrente do fluxo de estudantes de outros municípios, não devidamente compreendido, e do rápido desenvolvimento de Itaipu, segundo distrito de Niterói, que vem crescendo a taxas superiores a $10 \%$ a.a. Por outro lado, foram destacadas algumas áreas em que haveria pequenos desequilíbrios de vagas e áreas com absoluta escassez de vagas, mas em que predomina a população de renda elevada. Naturalmente, se tais segmentos mais privilegiados optarem pela escola pública,. poderá haver forte demanda reprimida.

\subsection{Ilha do Governador/RJ}

O estudo de localização de escolas realizado na Ilha do Governador, parte integrante da cidade do Rio de Janeiro, com cerca de 200.000 habitantes, e 228 setores censitários, fez uso intensivo dos sistemas de informação geográficos, especificamente o ArcView. A Ilha é um microcosmo que reproduz com notável precisão as contradições da cidade do Rio de Janeiro, com suas rupturas sócio econômicas e os problemas de habitação, saneamento, favelização, conflitos urbanos, transporte, desigualdades sociais etc, fornecendo um precioso ambiente para estudos urbanos e sociológicos.

Ao contrário dos municípios da região metropolitana, a Ilha encontra-se sob o controle da administração da cidade do Rio de Janeiro, de modo que, apesar de uma ocupação também rápida e desordenada, a cidade conseguiu oferecer a infra-estrutura básica quanto aos serviços públicos, o que muda muito a gravidade do problema educacional. Por outro lado, o importante segmento da classe média presente na região evita a freqüência às escolas próximas a favelas, selecionando certas escolas públicas ou buscando as escolas privadas. Como esse comportamento é mais transparente no início da educação ( $1^{\circ}$ segmento), o estudo desdobrou-se em dois: 1) avaliação do $1^{\circ}$ segmento, faixa etária 7-11 anos, e 2) avaliação do $2^{\circ}$ segmento, faixa etária 12-15 anos.

Das 31 escolas públicas na área, 16 trabalham somente com o $1^{\circ}$ segmento, 2 com somente o $2^{\circ}$ segmento e 13 possuem ambos. Foram feitas duas avaliações separadas relativas a cada segmento, notando-se que o fator distância é mais relevante para as crianças menores, e menos significativo para os alunos do $2^{\circ}$ segmento. $O$ estudo identificou uma importante escassez de vagas em ambos os segmentos, mas, como acima notado, não se trata de crianças 
fora do sistema, mas de crianças freqüentando escolas privadas. Por dificuldades de acesso a informações, com bloqueio ao fornecimento de dados oficiais, alguns resultados ficaram prejudicados, mas estima-se que a rede privada absorva cerca de $40 \%$ da população escolar. Mapas e desenhos e detalhes do estudo estão disponíveis em Bassil (2000) e no SBPO de 1999 (cf. Pizzolato et alii, 1999).

\subsection{Fortaleza/CE}

Uma outra importante aplicação foi feita na cidade de Fortaleza, com problemas semelhantes aos das grandes capitais e regiões metropolitanas. A cidade de Fortaleza é dividida em cinco distritos e em 1996 sua população correspondia a quase 2 milhões de habitantes, em uma área de $313,8 \mathrm{~km}^{2}$. A taxa de analfabetismo na época era de $16,8 \%$ para população de 15 anos ou mais, enquanto que a população de 7 a 14 anos estava em torno de 327.733 , ou $16,38 \%$ da população total.

O trabalho também executou as duas etapas, a avaliação da localização atual e a proposta de relocalização (Barros, 2000). Para resolver o problema da p-mediana, a heurística de Pizzolato (1994) foi implementada em um Sistema de Apoio à Decisão Espacial (S.A.D.E.), denominado GeoRedes (Barros Neto, 2002). Outra ferramenta SIG utilizada foi o MAPINFO 3.0 para a obtenção de mapas temáticos da população de 7 a 14 anos do município de Fortaleza.

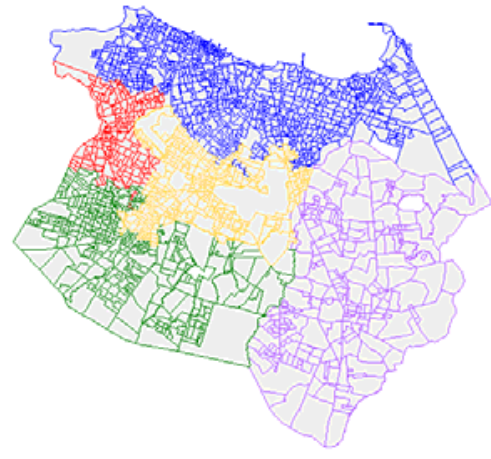

Figura 4 - Fortaleza por 1.861 Setores Censitários

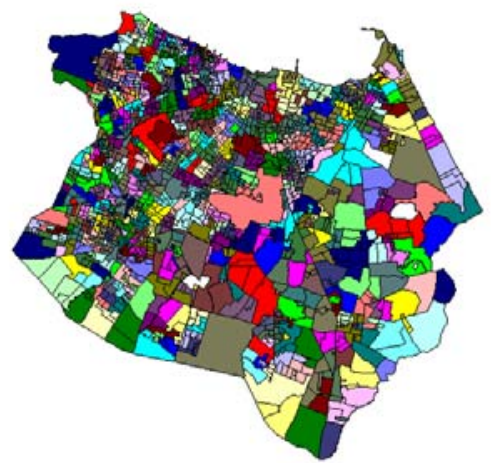

Figura 5 - Fortaleza por 503 Grupos de Setores Censitários

Foi utilizado um mapa georreferenciado dos setores censitários de Fortaleza, desenvolvido pelo IBGE, que, após pré-análise, resultou em 1.861 setores censitários. Por ser um município com um número excessivo de setores censitários, foi necessário fazer o agrupamento dos mesmos. Foram utilizados dois critérios de agrupamento: a distância máxima entre os geocentros dos setores censitários de $1.000 \mathrm{~m}$ e soma da população de 7 a 14 anos não superior a 1.000 habitantes.

No ano de 1998 encontravam-se ativas 332 escolas públicas e 806 particulares com ensino fundamental no município de Fortaleza. O estudo analisou apenas a localização de 256 escolas públicas, georreferenciadas, que se referem àquelas que funcionavam em prédios próprios. A metodologia proposta na Seção 2 foi aplicada, mas com diversas adaptações decorrentes da dimensão do problema, incompatível com as rotinas disponíveis. 
Assim, no Passo 1, os geocentros foram marcados, conforme mostrado na Figura 4. Com o agrupamento de setores censitários, e usando os critérios mencionados acima, os 1.861 setores censitários resultaram em 503 setores agrupados, conforme a Figura 5. Para cada conjunto de setores, ou grupos medianos, foram identificados novos geocentros, correspondendo aos novos vértices da rede, Figura 6. Cada geocentro é o ponto que, para efeitos do estudo, contém toda a população escolarizável (de 7 a 14 anos) do grupo, de acordo com os dados adquiridos junto ao IBGE.

Para o Passo 2 foram medidas as distâncias entre os geocentros determinados no passo anterior. No caso, a distância euclidiana, medida em metros.

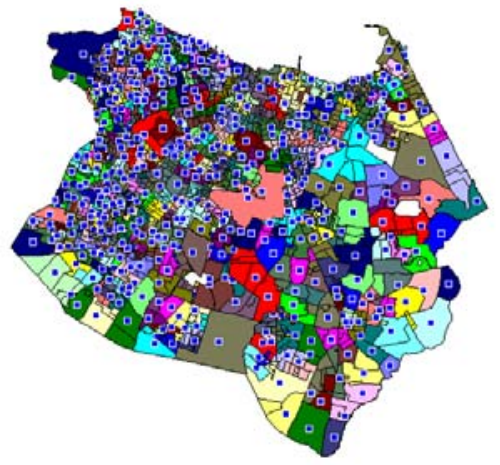

Figura 6 - Fortaleza por Grupos de Setores Censitários com Respectivos Geocentros

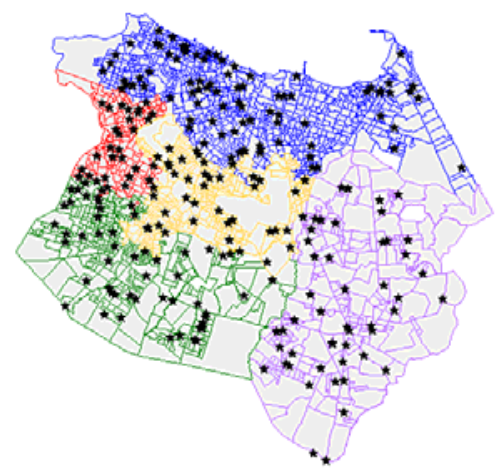

Figura 7 - Fortaleza por setores com 256 Escolas Georreferenciadas

De acordo com os Passos 3 e 5, foram feitas as avaliações da localização atual, como mostrado na Figura 7. Conhecida a localização de 256 escolas públicas, das 332 em atividade no ano de 1998, sobre geocentros específicos, foram determinados quais grupos que cada escola deveria atender e comparados com os grupos medianos sugeridos pelo modelo. Como resultado foi obtido o quanto a escola estava desequilibrada com relação à demanda colocada pelo grupo mediano.

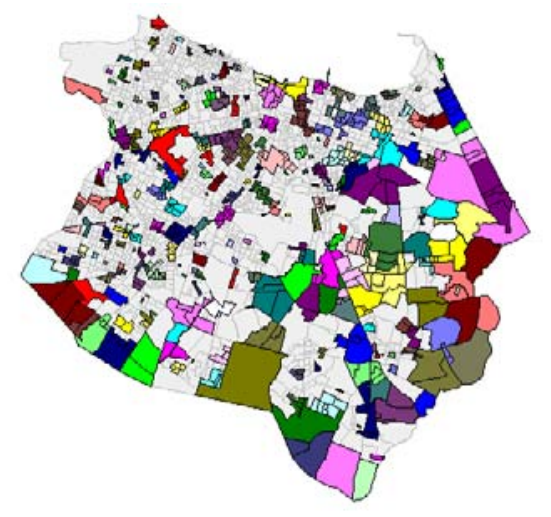

Figura 8 - Fortaleza por Grupos Medianos

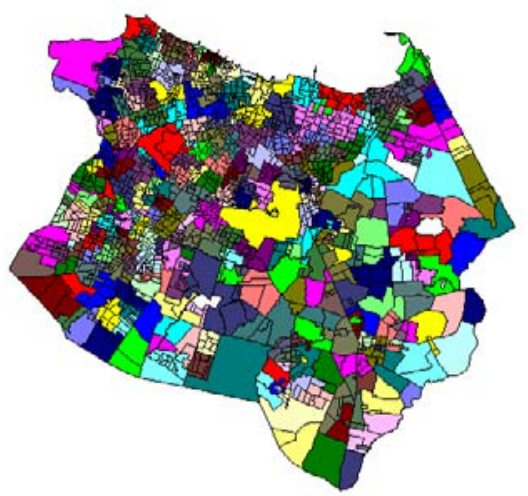

Figura 9 - Grupos de Setores Censitários por Grupos Medianos 
De acordo com os Passos 4 e 5 foi feita a proposta de relocalização das escolas. Com os dados de distância e de peso dos geocentros, o problema da p-mediana foi resolvido segundo a heurística de Pizzolato (1994), que determinou os grupos nos quais deveria existir pelo menos uma escola (grupos medianos) e a população que seria atendida por cada um deles. Dessa forma, a solução obtida indica:

a) Em quais grupos deveria existir pelo menos uma escola (Figura 8);

b) Para cada grupo mediano, quais grupos ele atenderia (Figura 9);

c) O total de alunos para cada grupo mediano (Figura 10) e

d) A distância média percorrida pelos alunos.

No Passo 6 foi feita a interpretação e apresentação dos resultados. Esses resultados estão expostos em forma de relatórios em Barros (2000). Alguns mapas temáticos reforçam esses resultados, com uma visualização dos mesmos. O grupo mediano de maior demanda total deveria atender a 4.802 jovens de 7 a 14 anos, seis outros entre 3.220 e 4.020 e vinte entre 2.420 e 3.220, o que pode ser visto na Figura 10. A distância média percorrida pelo total de jovens, é de $320 \mathrm{~m}$, mas representa uma subavaliação da realidade, devendo ser lembrado que as distâncias referentes aos alunos residentes nos grupos medianos, por simplificação metodológica, assumem valor zero.

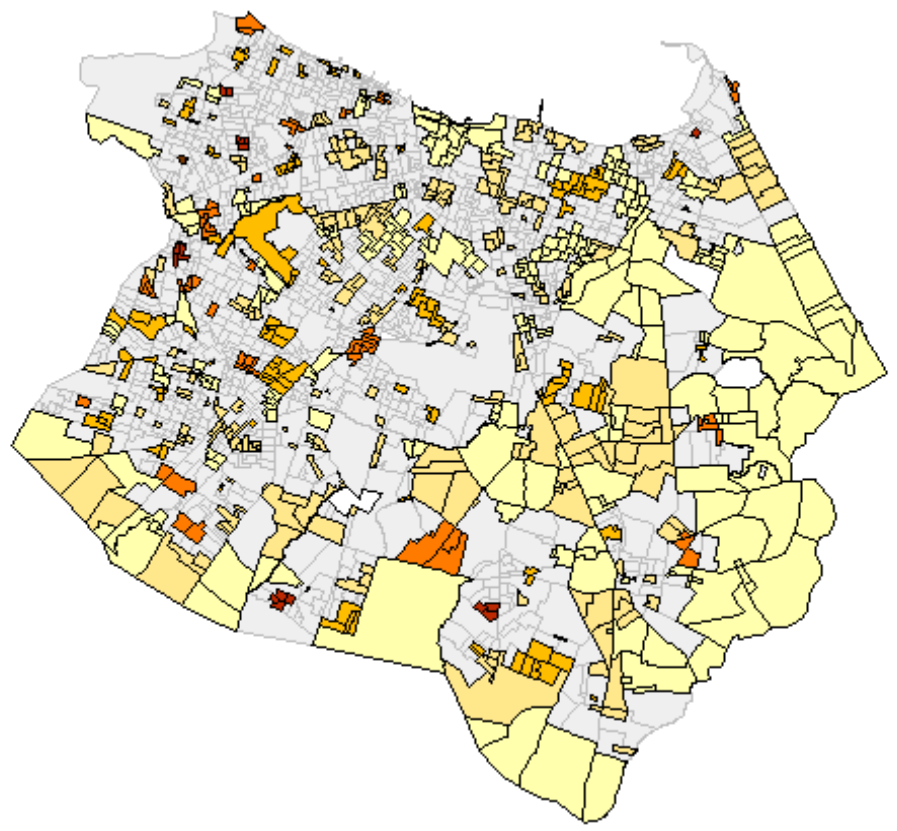

Pop 7 a14 Atendida pelo Grupo Mediano Fortaleza

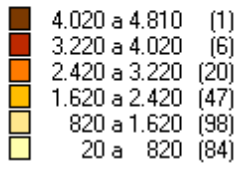

Figura 10 - População de 7 a 14 Anos Atendida pelo Grupo Mediano 
A localização real das 256 escolas foi analisada. Grupos foram alocados a elas, levando em conta o seu posicionamento. A maioria das escolas deveria atender entre 210 e 1.950 jovens de 7 a 14 anos. Sete dos grupos com escolas deveriam atender entre 3.690 e 4.560 , e o de n $^{\circ}$ 169, 5.409 jovens, necessitando portanto de mais de uma escola nos mesmos. Porém, apenas três deles tinham duas escolas em 1998 e o restante, apenas uma. Vale ressaltar aqui que o grupo com 5 escolas deveria atender a apenas 512 jovens e o de 4 escolas a 1.115 , ou seja, isso implica uma má distribuição das escolas (em prédios próprios). Aqui, a distância média percorrida pelos alunos resultou em $357 \mathrm{~m}$, ou seja, $11,56 \%$ superior à obtida pela citada heurística, com $\mathrm{p}=256$, enquanto que a maior distância observada foi de $1.789 \mathrm{~m}$.

O modelo foi executado também para localizar 332 escolas, porém sem considerar a existência das 256, devido à limitação do algoritmo utilizado. Neste caso, resultou que apenas 3 destes deveriam atender 3.000 ou mais jovens de 7 a 14 anos, uma população bem menor que o resultado para as 256 escolas. Em apenas 29 dos 332 grupos medianos a máxima distância foi maior que $500 \mathrm{~m}$ e a maior delas foi de $1.128 \mathrm{~m}$. A distância média resultou em 194m, uma redução de 39,37\% em relação ao modelo com 256 escolas.

Pode ser concluído por essa avaliação da localização das escolas em Fortaleza, que, para a real localização das 256 escolas ativas em 1998, em alguns grupos existiam mais do que uma escola, variando de 2 a 5, enquanto outros grupos tinham apenas uma escola, apesar de apresentarem população acima de 4.000 jovens de 7 a 14 anos. O grupo com 5 escolas deveria atender a apenas 512 jovens e, o de 4, a 1.115 crianças e adolescentes. É bastante evidente o contraste entre população em idade escolar e quantidade de escolas de ensino fundamental em vários grupos, o que evidencia a necessidade de um planejamento na distribuição de vagas. Esse planejamento pode implicar em ampliação ou construção de novas escolas (dependendo da existência ou não de escolas em prédios provisórios) ou remanejamento de algumas já existentes onde há excesso, como é o caso dos grupos com 4 e 5 escolas.

A real localização das escolas, e a sugerida pelo modelo utilizado nessa pesquisa, foram comparadas e resultou que somente $35 \%$ das mesmas estavam localizadas em grupos medianos sugeridos. Com esses resultados pode ser concluído que, considerando as escolas públicas que funcionavam em prédios próprios, há uma má distribuição espacial das mesmas no município de Fortaleza, sugerindo que as autoridades deveriam considerar essas análises, juntamente com a solução sugerida pelo modelo aqui utilizado. Seria, portanto, um importante instrumento para auxiliar na tomada de decisão quanto à construção de novas escolas, ou ampliação de algumas já existentes, conforme as que funcionam em prédios provisórios.

Certamente, são diversas as razões de crianças e adolescentes estarem fora da escola, como falta de vagas, dificuldades financeiras, trabalho precoce e desinteresse; não esquecendo também que muitos desses jovens já estiveram na escola e foram expulsos da mesma devido à própria natureza do sistema, marcado pelas altas taxas de repetência. Diante disso, é necessário então um conjunto de ações para melhorar o quadro educacional no Brasil. Muitas têm sido implantadas, talvez com abrangência e/ou qualidade aquém do que é necessário. Para complementar estas ações, o planejamento adequado da localização das escolas pode ser de grande auxílio na racionalização de recursos evitando construção de escolas onde a demanda já esteja suprida. 


\section{Conclusões}

O presente artigo aborda a problemática da localização de escolas em grandes áreas urbanas. O problema é de natureza universal, diante da imposição moderna de oferecer educação a todos os jovens. Nesse particular, o artigo faz um levantamento de aplicações análogas oferecidos pela literatura acadêmica internacional.

Em nosso país, o problema exibe grande atualidade, pois a educação é colocada como meta prioritária por todo governante, embora divergências entre o discurso e a prática sejam comuns. Das duas fases sugeridas pela metodologia, a avaliação da atual localização é a mais importante e útil, quando os desequilíbrios não chegam a ser graves, mas em casos como Nova Iguaçu, assim como em outros municípios das grandes regiões metropolitanas, após vários anos de crescimento populacional galopante, o estudo de relocalização é indispensável.

Os cinco estudos práticos reportados alcançaram ambientes urbanos variados, decorrentes de heranças culturais diversificadas e sujeitas a dinâmicas diferenciadas. No caso de Nova Iguaçu houve uma expansão demográfica anárquica, enquanto que em seu município vizinho, Nilópolis, geograficamente muito menor, foi preservada uma ordenação urbanística, que evitou a sobrecarga de problemas na oferta de serviços públicos. Niterói, por outro lado, como ex-capital, e altos níveis educacionais e econômicos, sempre teve uma personalidade própria, com significativa participação da população na administração pública. Na Ilha do Governador, a oferta é compatível com a demanda, com forte presença das escolas privadas, mas sujeita a importantes problemas sociais. Fortaleza, a maior das cidades estudadas, sofreu um crescimento populacional rápido, porém mais recente, resultado do desenvolvimento econômico privilegiado da capital do estado.

$\mathrm{Na}$ época de hoje, em que os processos migratórios internos se reduziram, a taxa de natalidade caiu substancialmente, e as cidades tendem a se estabilizar demograficamente, estudos de avaliação da distribuição espacial da rede são fortemente desejáveis. Trata-se de um aspecto importante da administração escolar, que pode estimular o desenvolvimento de outros elementos pedagógicos fundamentais e atenuar os problemas de desigualdades observadas nas redes de ensino público.

\section{Agradecimentos}

O primeiro autor agradece ao Conselho Nacional de Desenvolvimento Científico e Tecnológico - CNPq e à Fundação para o Amparo a Pesquisa no Estado do Rio de Janeiro FAPERJ - por apoio financeiro parcial.

\section{Referências Bibliográficas}

(1) Antunes, A.J.P. (1994). De la planification optimale de l'équipment scolaire. Dissertation en Sciences Appliquées, Université Catholique de Louvain, Louvain La-Neuve.

(2) Armstrong, M.P.; De, S.; Densham, P.J.; Lolonis, P.; Rushton, G. \& Tewari, V.K. (1990). A knowledge-based approach for supporting locational decision making. Environment and Planning B: Planning and Design, 17, 341-364. 
(3) Barcelos, F.B. (2002). Avaliação da localização de escolas com modelo capacitado e não capacitado e uso de uma ferramenta GIS: estudo de caso da cidade de Vitória/ES. Dissertação de mestrado, PUC/Rio.

(4) Bassil, K.W. (2000). Avaliação da localização de escolas públicas com o uso do GIS: estudo da Ilha do Governador. Dissertação de Mestrado, PUC/Rio.

(5) Banerji, S. \& Fisher, H.B. (1974). Hierarchical location analysis for integrated area planning in rural India. Papers of the Regional Science Association, 33, 177-194.

(6) Barros, A.G.P.O. (2000). Avaliação da capacidade e da localização de escolas públicas em Fortaleza. Tese M.Sc., Engenharia de Produção COPPE/UFRJ, Universidade Federal do Rio de Janeiro, RJ, Brasil.

(7) Barros Neto, J.F. (2002). Georedes e Georedes WEB: Sistemas de apoio à decisão espacial para modelos em redes georeferenciadas. Tese D.Sc., Engenharia de Produção COPPE/UFRJ, Universidade Federal do Rio de Janeiro, RJ, Brasil.

(8) Beguin, H.; Deconnink, J. \& Peeters, D. (1989). Optimizer la localization des ecoles primaires: le cas de Mouscron, Belgique. Revue d'Economie Regionale et Urbaine, 5, 795-806.

(9) Dutra, N.G.S. (1998). Planejando uma rede escolar municipal para reduzir custos de deslocamentos. Dissertação de Mestrado, Escola de Engenharia de São Carlos, Universidade de São Paulo.

(10) Fisher, H.B. \& Rushton, H.B. (1979). Spatial efficiency of service locations and the regional development process. Papers of the Regional Science Association, 42, 83-97.

(11) Galvão, R.D.; Acosta, L.G.E. \& Boffey, B. (2002). A hierarchical model for the location of perinatal facilities in the municipality of Rio de Janeiro. European Journal of Operational Research, 138, 495-517.

(12) Galvão, R.D. \& Raggi, L.A. (1989). A method for solving to optimality uncapacitated location problems. Annals of Operations Research, 18, 225-244.

(13) Lawler, E.L. (1976). Combinatorial Optimization: Network and Matroids. Holt, Rinehart, and Winston, New York.

(14) Molinero, C.M. (1988). Schools in Southampton: a quantitative approach to school location, closure and staffing. Journal of the Operational Research Society, 39(4), 339-350.

(15) Pizzolato, N.D. (1994). A heuristic for large-size p-median location problems with application to school location. Annals of Operations Research, 50, 473-485.

(16) Pizzolato, N.D. \& Silva, H.B.F. (1993). Proposta metodológica de localização de escolas: estudo do caso de Nova Iguaçu. Pesquisa Operacional, 14(2), 1-13.

(17) Pizzolato, N.D. \& Silva, H.B.F. (1997). The location of public schools: evaluation of practical experiences. International Transactions in Operations Research, 4(1), 13-22.

(18) Pizzolato, N.D.; Silva, G.G. \& Mizubuti, S. (1999). Avaliação da oferta de ensino fundamental pela rede pública e sua distribuição espacial: aplicação ao município de Niterói. Revista Brasileira de Estudos Pedagógicos, 80, 327-341. 
(19) Rahman, S. \& Smith, D.K. (1991). A comparison of two heuristic methods for the p-median problem with and without maximum distance constraints. International Journal of Operations \& Production Management, 11(6), 76-84.

(20) ReVelle, C.S. \& Swain, R.W. (1970). Central facilities location. Geographical Analysis, 2(1), 30-42.

(21) Silva, Guilherme G. (1995) Avaliação gerencial da localização de rede de ensino público de Niterói. Dissertação de Mestrado, Programa de Engenharia Civil, UFF.

(22) Silva, Hamilton, B.F. (1991). Planejamento da rede pública em áreas urbanas: um modelo matemático para localização de escolas. Dissertação de Mestrado, Programa de Engenharia Civil, UFF.

(23) Stock, R. (1983). Distance and utilization of health facilities in rural Nigeria. Social Science and Medicine, 17(9), 563-570.

(24) Tewari, V.K. (1992). Improving access to services and facilities in developing countries, International Regional Science Review, 15(1), 25-37.

(25) Tewari, V.K. \& Jena, S. (1987). High school location decision making in rural India and location-allocation models. In: Spatial Analysis and Location-Allocation Models [edited by A. Ghosh \& G. Rushton], New York, Van Nostrand Rheinhold.

(26) Vasconcellos, M.M. (1997). Modelos de localização e sistemas de informação geográficos na assistência materna e perinatal: uma aplicação no município do Rio de Janeiro. Tese de doutorado em Engenharia Biomédica, UFRJ.

(27) Viegas, J.M. (1987). Short and mid-term planning of an elementary school network in a suburb of Lisbon. Sistemi Urbani, 1, 57-77. 